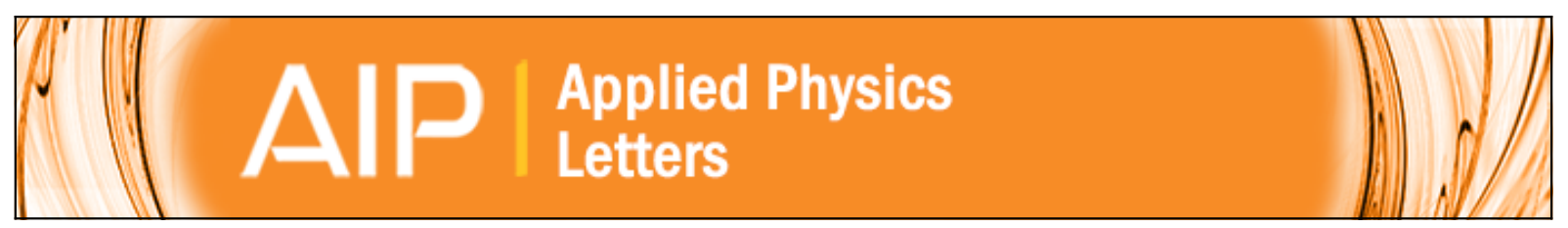

\title{
Pulsed laser deposition of Mn doped CdSe quantum dots for improved solar cell performance
}

Qilin Dai, Erwin M. Sabio, Wenyong Wang, and Jinke Tang

Citation: Applied Physics Letters 104, 183901 (2014); doi: 10.1063/1.4875107

View online: http://dx.doi.org/10.1063/1.4875107

View Table of Contents: http://scitation.aip.org/content/aip/journal/apl/104/18?ver=pdfcov

Published by the AIP Publishing

\section{Articles you may be interested in}

Green synthesis of highly efficient CdSe quantum dots for quantum-dots-sensitized solar cells

J. Appl. Phys. 115, 193104 (2014); 10.1063/1.4876118

Efficiency improvement of CdS and CdSe quantum dot-sensitized solar cells by TiO2 surface treatment

J. Renewable Sustainable Energy 6, 023107 (2014); 10.1063/1.4870996

Optimization of growth conditions of type-II $\mathrm{Zn}(\mathrm{Cd}) \mathrm{Te} / \mathrm{ZnCdSe}$ submonolayer quantum dot superlattices for intermediate band solar cells

J. Vac. Sci. Technol. B 31, 03C119 (2013); 10.1116/1.4797486

CdSe quantum dots synthesized by laser ablation in water and their photovoltaic applications Appl. Phys. Lett. 101, 223902 (2012); 10.1063/1.4768706

Improved efficiency of hybrid solar cells based on non-ligand-exchanged CdSe quantum dots and poly(3hexylthiophene)

Appl. Phys. Lett. 96, 013304 (2010); 10.1063/1.3280370

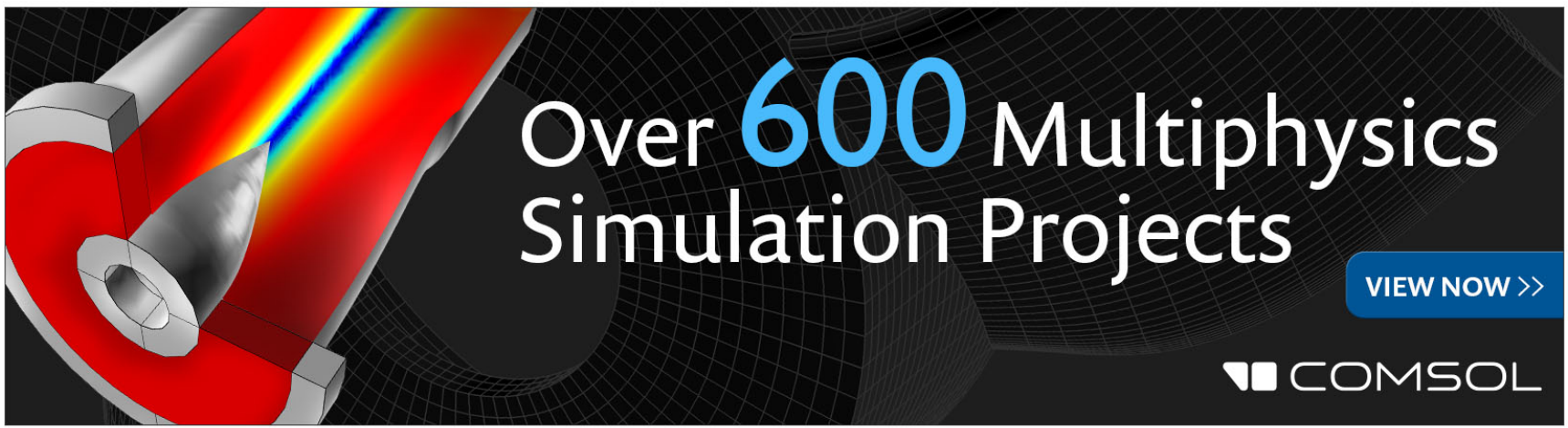




\title{
Pulsed laser deposition of Mn doped CaSe quantum dots for improved solar cell performance
}

\author{
Qilin Dai, ${ }^{1}$ Erwin M. Sabio, ${ }^{2}$ Wenyong Wang, ${ }^{1, \text { a) }}$ and Jinke Tang ${ }^{1, a)}$ \\ ${ }^{1}$ Department of Physics and Astronomy, University of Wyoming, Laramie, Wyoming 82071, USA \\ ${ }^{2}$ Department of Chemistry, University of Wyoming, Laramie, Wyoming 82071, USA
}

(Received 17 March 2014; accepted 23 April 2014; published online 5 May 2014)

\begin{abstract}
In this work, we demonstrate (1) a facile method to prepare Mn doped CdSe quantum dots (QDs) on $\mathrm{Zn}_{2} \mathrm{SnO}_{4}$ photoanodes by pulsed laser deposition and (2) improved device performance of quantum dot sensitized solar cells of the Mn doped QDs (CdSe:Mn) compared to the undoped QDs (CdSe). The band diagram of photoanode $\mathrm{Zn}_{2} \mathrm{SnO}_{4}$ and sensitizer CdSe:Mn QD is proposed based on the incident-photon-to-electron conversion efficiency (IPCE) data. Mn-modified band structure leads to absorption at longer wavelengths than the undoped CdSe QDs, which is due to the exchange splitting of the CdSe:Mn conduction band by the Mn dopant. Three-fold increase in the IPCE efficiency has also been observed for the Mn doped samples. (C) 2014 AIP Publishing LLC.

[http://dx.doi.org/10.1063/1.4875107]
\end{abstract}

Quantum dot sensitized solar cells (QDSSCs) are attracting much attention as they show promise toward the development of solar cells due to the unique properties of QDs such as the ability to match the solar spectrum, high absorption coefficient, and potential multiple electron generation effect. ${ }^{1-10}$ However, the power conversion efficiency (PCE) of a QDSSC is still quite low due to the less than desirable open circuit voltage, short-circuit current, and fill factor, especially when compared to the $\mathrm{Si}$ solar cells that have PCE of $10 \%-25 \% .{ }^{11}$ The highest PCE of QDSSC to date is $6.36 \%$ based on $\mathrm{CdSe}_{\mathrm{x}} \mathrm{Te}_{1-\mathrm{x}}$ alloy QDs according to the literature. ${ }^{12}$

Research efforts have been focused on improving the PCE using bilayer electrodes, energy transfer from QDs to dyes, and dopants to modify intrinsic property of QDs. ${ }^{13-15}$ The electronic, optical, and photophysical properties of QDs might be modified through doping to make the QDSSCs better devices. Santra and Kamat developed a strategy to boost efficiency over 5\% by Mn doped CdS QDs in 2012. ${ }^{16}$ The midgap states created by dopants may have long lifetimes to allow more carriers to be injected to the photoanode to improve the PCE. For Mn doped CdSe QDs (CdSe:Mn), their optical and magnetic properties have been widely studied. ${ }^{17-20}$ Light-induced spontaneous magnetization of Mn doped (4.5\%) CdSe QDs was suggested by Gamelin et al. ${ }^{21}$ Size-dependent magnetic exchange coupling was observed in $0.6 \% \mathrm{Mn}$ doped CdSe QDs by Zheng and Strouse. ${ }^{22}$ We aim to explore the effects of Mn-modified electronic structure on the QDSSC characteristics. The number of methods for the synthesis of QDs with effective Mn doping is limited due to self-purification of QDs. ${ }^{23}$ In our previous work, a one-step QD synthesis and assembly approach based on pulsed laser deposition (PLD) technique has been developed to make $\mathrm{CdSe}$ and $\mathrm{PbS}$ QDs for photovoltaic applications. ${ }^{24,25}$ In this work, we show that this facile method is very effective to synthesize Mn doped CdSe

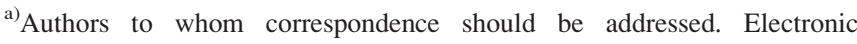
addresses: wwang5@uwyo.edu and jtang2@uwyo.edu.
}

QDs. In addition, improved QDSSC device performance based on CdSe:Mn QDs was obtained in comparison to that based on CdSe QDs, which is attributed to the reduced band gap by Mn due to exchange splitting. Other factors responsible for the increased incident-photon-to-electron conversion efficiency (IPCE) efficiency are also discussed. The experimental part can be found in supplementary material. ${ }^{26}$

Figures 1(a) and 1(b) show the low-magnification and high-magnification TEM images of CdSe:Mn QDs on $\mathrm{Zn}_{2} \mathrm{SnO}_{4}$ nanowires, respectively. It can be seen that CdSe:Mn QDs were homogeneously deposited on the $\mathrm{Zn}_{2} \mathrm{SnO}_{4}$ nanowire surface by PLD (Figure 1(a)). Discrete QDs on the nanowires (Figure 1(b)) are suitable for solar cell applications since QD aggregation would lead to quenching of the quantum confinement effect due to the overlapping electron wave functions. ${ }^{27-29}$ To further investigate the size distribution and microstructures of the CdSe:Mn QDs, TEM images of QDs deposited on amorphous carbon TEM grids were obtained (Figures 1(c) and 2(d)). The same deposition parameters were used. From the statistical analysis of CdSe:Mn QDs (Figure 1(c), inset), it can be seen that the CdSe:Mn QDs have an average diameter of $4.4 \mathrm{~nm}$, which is smaller than the $5.5 \mathrm{~nm}$ CdSe QDs made with the same deposition parameters. ${ }^{24}$ The doping induced strains, surface charge modification, or changes in the diffusion process may be some of the possible reasons for the observed smaller size of CdSe:Mn QDs. ${ }^{30-32}$ Figure 1(d) is a high-resolution TEM image that shows the lattice fringes of the (111) planes of the CdSe:Mn QDs. The d spacing of the (111) lattice planes is $\sim 0.35 \mathrm{~nm}$ for CdSe:Mn QDs as indicated. The $\mathrm{Mn}^{2+}$ ions should substitute $\mathrm{Cd}^{2+}$ ions during the growth of CdSe:Mn QDs. ${ }^{33} \mathrm{Mn}$ doping in the CdSe quantum dots is indicated from the energy dispersive x-ray spectroscopy (EDS) data (Figure $\mathrm{S} 1$ and Table I in supplementary material), which show $6.8+0.6$ at. $\% \mathrm{Mn}$ in CdSe QDs. ${ }^{26}$ Different areas (micrometer size) were chosen to collect the EDS spectra. The spectra from different areas are similar to each other. Quantitative analysis also shows that the atomic ratio of cation $(\mathrm{Cd}$ and $\mathrm{Mn})$ to anion $(\mathrm{Se})$ is 1:1.04, indicating good 

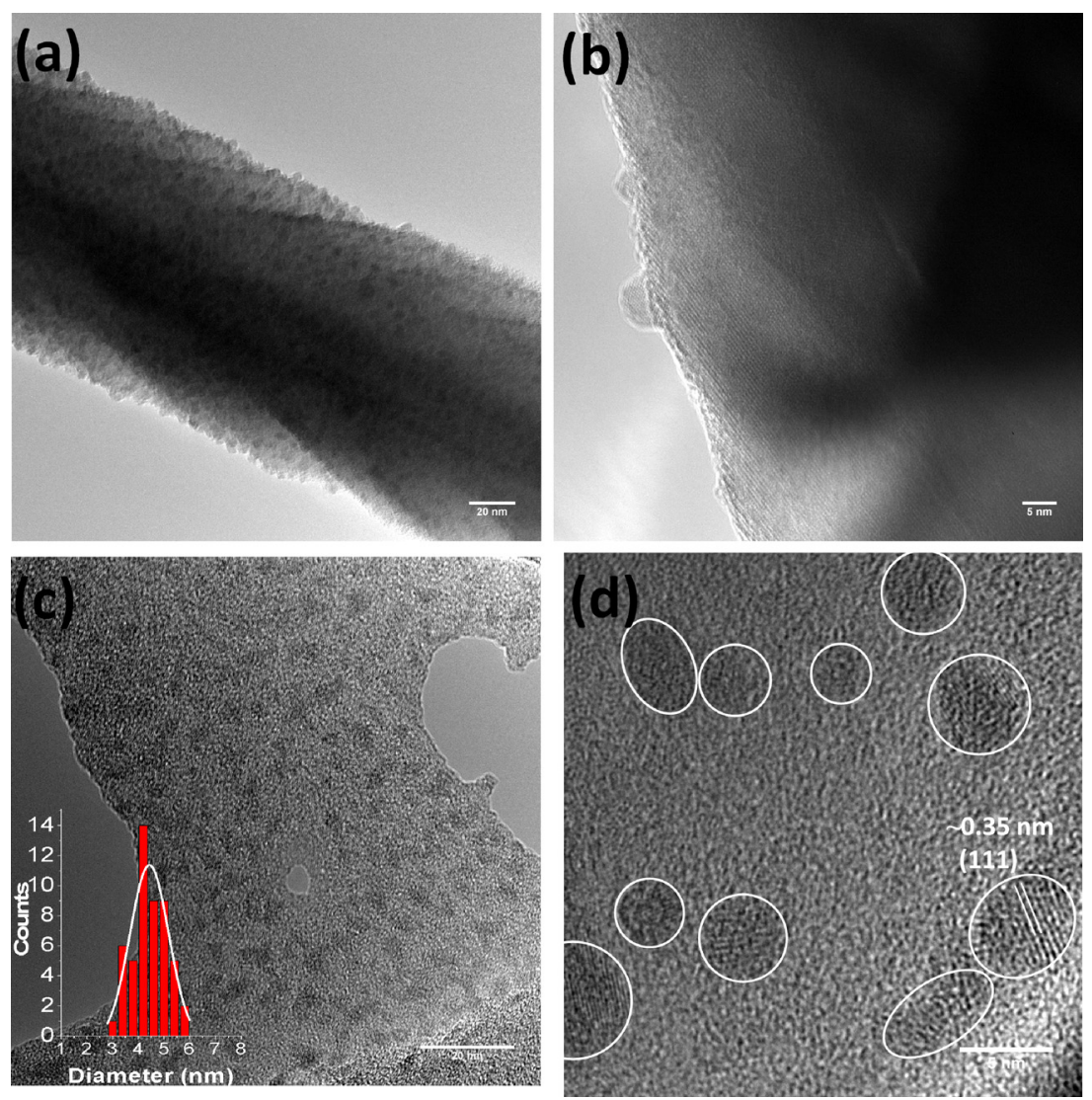

FIG. 1. (a) and (b) are low and high magnification TEM images of a $\mathrm{Zn}_{2} \mathrm{SnO}_{4}$ nanowire coated with CdSe: Mn QDs prepared by PLD. (c) and (d) are low and high magnification TEM images of CdSe:Mn QDs on amorphous carbon grid. The (111) crystal planes of the CdSe:Mn QDs are indicated. (c) Inset shows the size distribution of CdSe:Mn QDs on a carbon grid.

stoichiometry of the deposited CdSe:Mn QDs. The XRD pattern of CdSe:Mn QDs made by pulsed laser deposition on $\mathrm{Si}$ substrate (Figure S2) can be found in supplementary material. $^{26}$ The diffraction peaks from the CdSe:Mn QDs are very broad due to the QDs' small size. CdSe has two crystalline phases: hexagonal (wurtzite) or cubic (zinc-blende). The cubic phase is more stable than hexagonal phase at room temperature, but it can transform to the hexagonal structure at temperatures higher than $\sim 95^{\circ} \mathrm{C}$. ${ }^{34}$ The hexagonal phase has an extra peak at about $45^{\circ}$ compared to the cubic phase, which can be used to distinguish these two phases. The CdSe:Mn QDs are in the cubic phase, which is consistent with our previous CdSe QDs made by PLD method. ${ }^{24}$

Another confirmation of Mn doping in CdSe is provided by XPS data. CdSe:Mn QDs were deposited on Si substrate for the XPS measurement. Before the measurement, CdSe:Mn QD samples were sputter cleaned for different

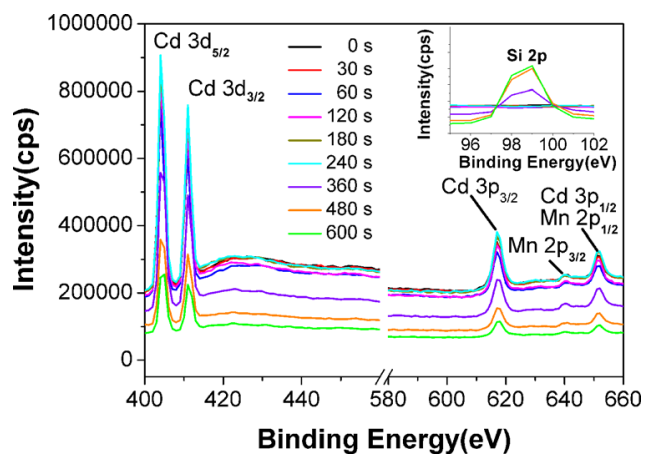

FIG. 2. XPS spectra of CdSe:Mn with different sputtering times. time periods to remove the surface layers of QDs to different degrees to allow the probe of Mn concentration as a function of the depth from the surface. Figure 2 shows the XPS data with different sputtering time. The signal of $\mathrm{Si}$ can be observed when the sputtering time exceeded $240 \mathrm{~s}$ indicating the time scale when the entire QDs are removed (Figure 2, inset). 6.7 at. \% Mn in CdSe QDs was determined before the sputtering (Table II in supplementary material), ${ }^{26}$ which suggests the Mn concentration is $6.7 \%$ on the surface and is consistent with the EDS data. The Mn concentration decreases to $\sim 4 \%$ as the sample was sputtered for $30 \mathrm{~s}$ and remains at that level as the sputtering time increased from 30 to $240 \mathrm{~s}^{26}$ This indicates the actual Mn doping concentration in the interior of the QDs is close to or less than 4\%. The result shows that PLD is an effective method for doping $\mathrm{Mn}$ in CdSe QDs at a substantial level. PLD is known to be a nonequilibrium process that fosters enhanced solubility of dopants in the hosts. ${ }^{35}$ The analysis of the Mn $2 p$ peaks in XPS as a function of the distance from the surface points to the presence of primarily $3+$ state, or a mixture of $3+/ 2+$ on the surface and an increased fraction of $\mathrm{Mn}^{2+}$ as we probe into the interior of the CdSe:Mn quantum dot film (Table III in supplementary material). ${ }^{26}$ With the reasonable assumption that atoms are more or less equally distributed on the surface and in the interior for particles of our size, the table suggests $\mathrm{Mn}$ atoms are primarily in the $2+$ state in the interior. The shift and broad shape of the Mn $2 \mathrm{p}_{3 / 2}$ peak preclude to presence of metallic Mn, which has a sharp peak at $639 \mathrm{eV}$ with no satellite on the low kinetic energy side of the peak. Thus, we believe that the $\mathrm{Mn}$ in the interior of the QDs is mainly in a $2+$ oxidation state. The growth mechanism of CdSe:Mn QDs on $\mathrm{Zn}_{2} \mathrm{SnO}_{4}$ nanowires is believed to be the 
Volmer-Weber (island) growth model which is caused by the large lattice mismatch and the low wettability between the two materials $\left(\mathrm{CdSe}\right.$ and $\left.\mathrm{Zn}_{2} \mathrm{SnO}_{4}\right){ }^{36}$ During the growth, the formation of three dimensional adatom islands can be explained by the stronger adatom-adatom interactions in comparison to the interactions between the adatoms and the substrate surface.

To further confirm Mn doping in the CdSe QD crystal lattice, Raman spectra of CdSe:Mn QDs and CdSe QDs were studied and the results are shown in Figure S3(a) in supplementary material. ${ }^{26} \mathrm{CdSe}$ QDs have the typical $\mathrm{LO}_{2}$ mode at $212 \mathrm{~cm}^{-1}$ in the Raman spectrum. ${ }^{37}$ The $\mathrm{LO}_{2}$ mode shifted to the $207 \mathrm{~cm}^{-1}$ as the Mn was doped in the CdSe QDs due to the formation of MnSe mode, which is consistent with the results in reported literature. ${ }^{38}$ Thus, it can be concluded that Mn ions were doped in the CdSe QD crystal lattice. In addition to confinement, Raman spectrum line width is also related to the size distribution, strain, low crystallinity, and shape irregularity. ${ }^{39,40} \mathrm{CdSe}$ quantum dots have broader size distribution than CdSe:Mn which can be seen from Figure 1(c) and Figure S4 in supporting information of Ref. 24. It is possible that broader size distribution causes broader Raman peak for the CdSe quantum dots. The magnetization of CdSe:Mn QDs is shown at low temperature in Figures S3(b) and S3(c) in supplementary material. ${ }^{26}$ It can be seen that the magnetization of CdSe:Mn QDs increased rapidly when the temperature was below $50 \mathrm{~K}$, which is typical paramagnetic behavior originating from the Mn local moments. The plot of $1 / \mathrm{M}$ versus $\mathrm{T}$ shown in Figure S3(c) gives negative intercept on the $\mathrm{T}$ axis indicating antiferromagnetic interactions between the $\mathrm{Mn}$ moments in the CdSe:Mn QDs in the ground state.
Figure 3(a) shows the IPCE spectra of the solar cell device based on CdSe:Mn and CdSe QDs (the undoped $\mathrm{CdSe}$ QDs are $5.5 \mathrm{~nm}$ in diameter and were prepared under the same conditions ${ }^{24}$ ). Both IPCE spectra show monotonic increase with increasing incident photon energy from 700 to $400 \mathrm{~nm}$. The absence of the excitonic features near $580-600 \mathrm{~nm}$ associated with the light absorption by 4.4-5.5 nm CdSe QDs is attributed to the broad size distribution of the PLD deposited QDs. ${ }^{24,25}$ Similar phenomenon has also been observed in QDSSCs prepared by the successive ionic layer adsorption and reaction method, and it has been confirmed that the absence of the excitonic features is not due to the quality of devices. ${ }^{41}$ It can be seen that the IPCE of the device based on CdSe:Mn QDs is on average more than three times enhanced compared to that of $\mathrm{CdSe}$ QDs, and the onset wavelength is redshifted resulting in widened absorption window. These enhancements of the IPCE for CdSe:Mn QDs are attributed to the additional absorption due to the incorporation of $\mathrm{Mn}^{2+}$ in the CdSe lattice, and we now discuss the details of the mechanisms for the enhancements.

The onset of the IPCE curve is associated with the size and the band gap of the QDs. ${ }^{24,41}$ Figure 3(b) shows the detailed IPCE in the region of the onset. The onset of the IPCE for the $5.5 \mathrm{~nm}$ CdSe QDs is $\sim 590 \mathrm{~nm}$ which is consistent with its band gap $(\sim 2.0 \mathrm{eV})$. The onset redshifts to $\sim 650 \mathrm{~nm}$, corresponding to a band gap of $\sim 1.9 \mathrm{eV}$, as the $\mathrm{Mn}^{2+}$ is doped in CdSe QDs. Based on the TEM images, the size of CdSe:Mn QDs is $4.4 \mathrm{~nm}$ indicating an expected band gap of $\sim 2.1 \mathrm{eV} .{ }^{42,43}$ Thus, the band gap of $\sim 1.9 \mathrm{eV}$ (a reduction of $0.2 \mathrm{eV}$ ) cannot be explained by the size of the CdSe:Mn

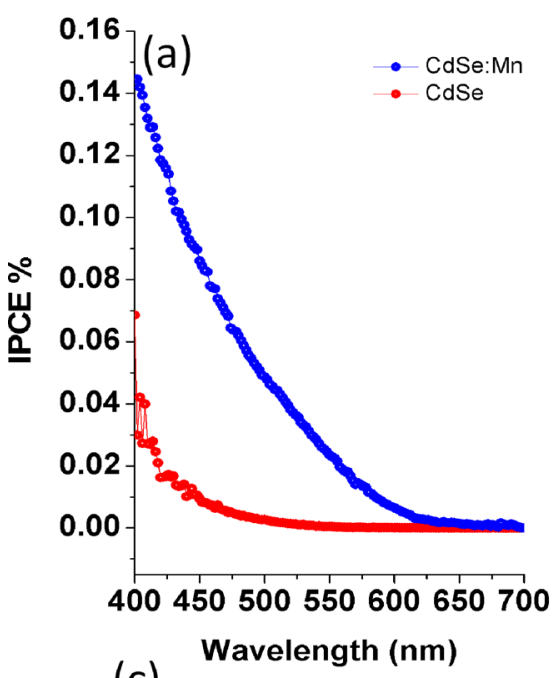

(c)

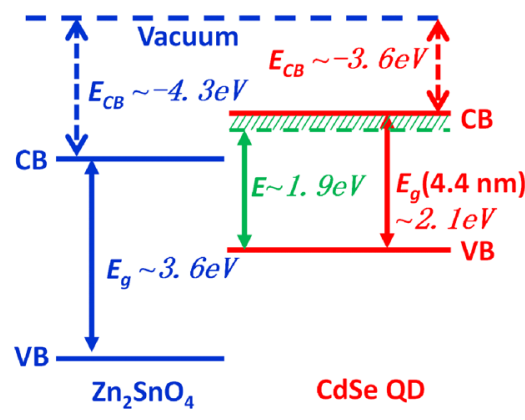

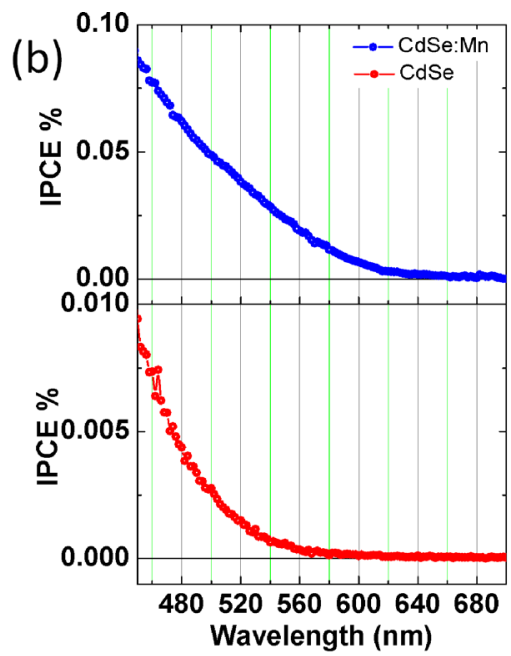

(d)

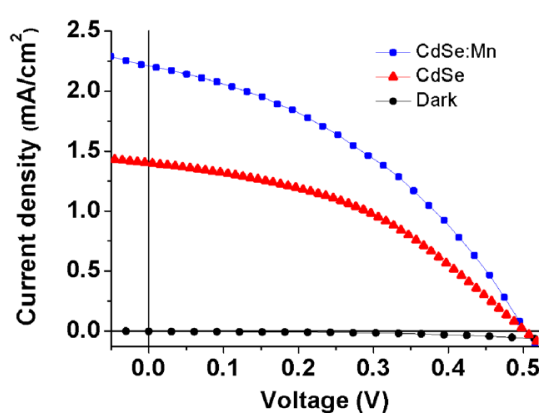

FIG. 3. (a) IPCE spectra of QDSSCs based on CdSe:Mn and CdSe QDs. (b) Details of the IPCE in the region of the onset. (c) The band diagrams of $\mathrm{Zn}_{2} \mathrm{SnO}_{4}, \mathrm{CdSe}$, and CdSe:Mn QDs. Red indicates the energy levels of undoped CdSe QDs. Green indicates the energy levels modified by $\mathrm{Mn}$ via exchange coupling. (d) $J-V$ curves of QDSSCs based on CdSe:Mn and CdSe QDs. 
QDs. It is known that Mn doping in II-VI semiconductor QDs induces giant Zeeman splitting due to the quantum confinement effect. ${ }^{44}$ The effective magnetic field produced by the Mn doping may reach as high as thousands of tesla, and the exchange splitting of the spin-up and spin-down bands can be of the order of $100 \mathrm{meV}$. In CdSe:Mn, very large effective magnetic fields were observed that lead to photoinduced complete magnetization of the QDs in the absence of an external magnetic field. ${ }^{21}$ Since a reliable spin-resolved band structure calculation on the band gap of CdSe:Mn is lacking, it is difficult to compare our experimental results with theories. Nevertheless, it can be unambiguously argued that the reduced band gap by $\sim 200 \mathrm{meV}$ is due to the exchange splitting of the conduction band by the $\mathrm{Mn}$. Another possible scenario is the introduction of intermediate bands in CdSe by the doped Mn, which result in additional absorption. $^{33}$ Calculations by Wei and Zunger confirm the absorption from the intermediate band of $\mathrm{Mn}$ in CdTe. ${ }^{45}$ Santra and Kamat also proposed that the midgap states created by Mn doping in CdS QDs could enhance the performance of QDSSCs. ${ }^{16}$ However, for CdSe, calculations by Beaulac et al. do not place the $3 \mathrm{~d}$ band of $\mathrm{Mn}$ inside the band gap. ${ }^{46}$ Model proposed in Ref. 21 also suggests the Mn $3 \mathrm{~d}$ states do not form midgap states in CdSe for the QDs of our sizes. Therefore, we believe the onset at $\sim 650 \mathrm{~nm}$ $(\sim 1.9 \mathrm{eV})$ is attributed to the absorption due to the reduced band gap of CdSe:Mn. Figure 3(c) shows the band diagrams of $\mathrm{Zn}_{2} \mathrm{SnO}_{4}$ nanowires, CdSe QDs, and CdSe:Mn QDs. The energy levels of CdSe:Mn QDs are proposed based on the IPCE results. According to the literature, the conduction band edge of the $\mathrm{Zn}_{2} \mathrm{SnO}_{4}$ nanowire is $\sim 4.3 \mathrm{eV}$ below the vacuum level. ${ }^{47}$ Undoped CdSe QDs having a mean diameter of $4.4 \mathrm{~nm}$ should have a band gap of $\sim 2.1 \mathrm{eV}$ with the conduction band edge $\sim 3.6 \mathrm{eV}$ below the vacuum level. ${ }^{48}$ That is, the conduction band edge of the $4.4 \mathrm{~nm} \mathrm{CdSe} \mathrm{QDs} \mathrm{is}$ $\sim 0.7 \mathrm{eV}$ higher than that of the $\mathrm{Zn}_{2} \mathrm{SnO}_{4}$ nanowires. With Mn doping, the band gap of the CdSe:Mn QDs is reduced to $1.9 \mathrm{eV}$, and its conduction band edge is $\sim 0.5 \mathrm{eV}$ above the conduction band edge of $\mathrm{Zn}_{2} \mathrm{SnO}_{4}$, which still facilitates easy injection of the photoexcited electrons from CdSe:Mn into the conduction band of the $\mathrm{Zn}_{2} \mathrm{SnO}_{4}$ nanowires. Besides extending the absorption window toward longer wavelength, Mn doping also induces additional states associated with the Mn 3d and 4s states as well as modifying the CdSe band structure through hybridization and exchange coupling. Not only do they provide additional absorption bands but also pathways for election injection which lead to the observed three-fold improvement in the IPCE.

Enhanced performance of the QDSSCs has been obtained with the Mn doped CdSe QDs. Figure 3(d) shows the $J-V$ curves of the QDSSCs based on CdSe:Mn and CdSe QDs. The short-circuit current density increased from 1.4 to $2.2 \mathrm{~mA} / \mathrm{cm}^{2}$ as Mn was doped into CdSe QDs. The detailed performance parameters of the QDSSCs are listed in Table IV in supplementary material. ${ }^{26}$ The efficiency of the QDSSCs based on CdSe:Mn increased by one and half times compared to CdSe QDs due to the increased and extended absorption from the Mn-induced states.

In summary, Mn doped CdSe QDs were prepared by PLD technique, which is an effective and easy method for the preparation of Mn doped in CdSe QDs overcoming the problem of self-purification. The QDSSC devices based on CdSe:Mn and CdSe QDs were investigated and compared. Improved short-circuit current and IPCE were observed and attributed to the Mn doping. The band gap is reduced from $2.1 \mathrm{eV}$ of the undoped $\mathrm{CdSe}$ to $1.9 \mathrm{eV}$ of $\mathrm{CdSe}: \mathrm{Mn}$ due to exchange splitting of the conduction band by Mn. Mnmodified density of states also provides additional absorption bands as well as pathways for election injection into the conduction band of the $\mathrm{Zn}_{2} \mathrm{SnO}_{4}$ photoanode. Our result points to a method to improve the solar cell conversion efficiency.

This work was supported by the U.S. Department of Energy, Office of Basic Energy Sciences, Division of Materials Sciences and Engineering under Award DE-FG0210ER46728.

${ }^{1}$ I. J. Kramer and E. H. Sargent, ACS Nano 5(11), 8506-8514 (2011).

${ }^{2}$ L. Li, X. C. Yang, J. J. Gao, H. N. Tian, J. Z. Zhao, A. Hagfeldt, and L. C. Sun, J. Am. Chem. Soc. 133(22), 8458-8460 (2011).

${ }^{3}$ Z. S. Yang, C. Y. Chen, C. W. Liu, C. L. Li, and H. T. Chang, Adv. Energy Mater. 1(2), 259-264 (2011).

${ }^{4}$ G. Zhu, L. K. Pan, T. Xu, and Z. Sun, ACS Appl. Mater. Interfaces 3(8), 3146-3151 (2011).

${ }^{5}$ H. K. Wang, C. Y. Luan, X. Q. Xu, S. V. Kershaw, and A. L. Rogacht, J. Phys. Chem. C 116(1), 484-489 (2012).

${ }^{6}$ H. N. Chen, L. Q. Zhu, H. C. Liu, and W. P. Li, J. Phys. Chem. C 117(8), 3739-3746 (2013).

${ }^{7}$ M. S. de la Fuente, R. S. Sanchez, V. Gonzalez-Pedro, P. P. Boix, S. G. Mhaisalkar, M. E. Rincon, J. Bisquert, and I. Mora-Sero, J. Phys. Chem. Lett. 4(9), 1519-1525 (2013).

${ }^{8}$ M. S. Faber, K. Park, M. Caban-Acevedo, P. K. Santra, and S. Jin, J. Phys. Chem. Lett. 4(11), 1843-1849 (2013).

${ }^{9}$ K. E. Roelofs, T. P. Brennan, J. C. Dominguez, C. D. Bailie, G. Y. Margulis, E. T. Hoke, M. D. McGehee, and S. F. Bent, J. Phys. Chem. C 117(11), 5584-5592 (2013).

${ }^{10}$ H. M. Zhu, N. H. Song, and T. Q. Lian, J. Am. Chem. Soc. 135(31), 11461-11464 (2013).

${ }^{11}$ M. A. Green, K. Emery, Y. Hishikawa, W. Warta, and E. D. Dunlop, Prog. Photovoltaics 20(1), 12-20 (2012).

${ }^{12}$ Z. X. Pan, K. Zhao, J. Wang, H. Zhang, Y. Y. Feng, and X. H. Zhong, ACS Nano 7(6), 5215-5222 (2013).

${ }^{13}$ S. Buhbut, S. Itzhakov, E. Tauber, M. Shalom, I. Hod, T. Geiger, Y. Garini, D. Oron, and A. Zaban, ACS Nano 4(3), 1293-1298 (2010).

${ }^{14}$ S. Buhbut, S. Itzhakov, D. Oron, and A. Zaban, J. Phys. Chem. Lett. 2(15), 1917-1924 (2011).

${ }^{15}$ H. Choi, R. Nicolaescu, S. Paek, J. Ko, and P. V. Kamat, ACS Nano 5(11), 9238-9245 (2011).

${ }^{16}$ P. K. Santra and P. V. Kamat, J. Am. Chem. Soc. 134(5), 2508-2511 (2012).

${ }^{17}$ J. J. Zheng, X. Yuan, M. Ikezawa, P. T. Jing, X. Y. Liu, Z. H. Zheng, X. G. Kong, J. L. Zhao, and Y. Masumoto, J. Phys. Chem. C 113(39), 16969-16974 (2009).

${ }^{18}$ R. Viswanatha, J. M. Pietryga, V. I. Klimov, and S. A. Crooker, Phys. Rev. Lett. 107(6), 067402 (2011).

${ }^{19}$ C. Le Gall, L. Besombes, H. Boukari, R. Kolodka, J. Cibert, and H. Mariette, Phys. Rev. Lett. 102(12), 127402 (2009).

${ }^{20}$ D. J. Norris, N. Yao, F. T. Charnock, and T. A. Kennedy, Nano Lett. 1(1), 3-7 (2001).

${ }^{21}$ R. Beaulac, L. Schneider, P. I. Archer, G. Bacher, and D. R. Gamelin, Science 325(5943), 973-976 (2009).

${ }^{22}$ W. W. Zheng and G. F. Strouse, J. Am. Chem. Soc. 133(19), 7482-7489 (2011).

${ }^{23}$ G. M. Dalpian and J. R. Chelikowsky, Phys. Rev. Lett. 96(22), 226802 (2006).

${ }^{24}$ Q. L. Dai, J. J. Chen, L. Y. Lu, J. K. Tang, and W. Y. Wang, Nano Lett. 12(8), 4187-4193 (2012).

${ }^{25}$ Q. L. Dai, J. J. Chen, L. Y. Lu, J. K. Tang, and W. Y. Wang, Appl. Phys. Lett. 102(20), 203904 (2013).

${ }^{26}$ See supplementary material at http://dx.doi.org/10.1063/1.4875107 for experimental part, Table I: Mn concentration from the EDS data, Table II: 
Mn concentration from XPS, Table IIII: the $\mathrm{Mn}^{2+}$ and $\mathrm{Mn}^{3+}$ ratio analysis in XPS, Table IV: Performance parameters of the QDSSCs, Figure S1: The EDS spectrum of CdSe:Mn QDs, Figure S2: XRD pattern of CdSe:Mn quantum dots, and Figure S3: (a) Raman spectra of CdSe:Mn and CdSe QDs. (b) Magnetization as a function of temperature for CdSe:Mn QDs. (c) Inverse magnetization as a function of temperature for CdSe:Mn QDs.

${ }^{27}$ O. I. Micic, C. J. Curtis, K. M. Jones, J. R. Sprague, and A. J. Nozik, J. Phys. Chem. 98(19), 4966-4969 (1994).

${ }^{28}$ W. R. Algar and U. J. Krull, ChemPhysChem 8(4), 561-568 (2007).

${ }^{29}$ Y. Zhang, L. Mi, P. N. Wang, J. Ma, and J. Y. Chen, J. Lumin. 128(12), 1948-1951 (2008).

${ }^{30}$ M. W. Wang, L. D. Sun, X. F. Fu, C. S. Liao, and C. H. Yan, Solid State Commun. 115(9), 493-496 (2000).

${ }^{31}$ F. Wang, Y. Han, C. S. Lim, Y. H. Lu, J. Wang, J. Xu, H. Y. Chen, C. Zhang, M. H. Hong, and X. G. Liu, Nature 463(7284), 1061-1065 (2010).

${ }^{32}$ J. H. Lee and B. O. Park, Mater. Sci. Eng., B 106(3), 242-245 (2004).

${ }^{33}$ L. H. Tang, J. Appl. Phys. 38(12), 4929 (1967).

${ }^{34}$ V. A. Fedorov, V. A. Ganshin, and Y. N. Korkishko, Phys. Status Solidi A 126(1), K5-K7 (1991).

${ }^{35}$ H. Saeki, H. Tabata, and T. Kawai, Solid State Commun. 120(11), 439-443 (2001).
${ }^{36}$ M. Ohring, Materials Science of Thin Films: Deposition and Structure (San Diego, 2002).

${ }^{37}$ J. E. B. Katari, V. L. Colvin, and A. P. Alivisatos, J. Phys. Chem. 98(15), 4109-4117 (1994).

${ }^{38}$ R. G. Alonso, Y. R. Lee, E. Oh, A. K. Ramdas, H. Luo, N. Samarth, J. K. Furdyna, and H. Pascher, Phys. Rev. B 43(12), 9610-9620 (1991).

${ }^{39}$ V. M. Dzhagan, M. Y. Valakh, A. E. Raevskaya, A. L. Stroyuk, S. Y. Kuchmiy, and D. R. T. Zahn, Nanotechnology 19(30), 305707 (2008).

${ }^{40}$ J. E. Spanier, R. D. Robinson, F. Zheng, S. W. Chan, and I. P. Herman, Phys. Rev. B 64(24), 245407 (2001).

${ }^{41}$ H. Lee, M. K. Wang, P. Chen, D. R. Gamelin, S. M. Zakeeruddin, M. Gratzel, and M. K. Nazeeruddin, Nano Lett. 9(12), 4221-4227 (2009).

${ }^{42}$ J. Jasieniak, M. Califano, and S. E. Watkins, ACS Nano 5(7), 5888-5902 (2011).

${ }^{43}$ S. Baskoutas and A. F. Terzis, J. Appl. Phys. 99(1), 013708 (2006).

${ }^{44}$ A. L. Efros and M. Rosen, Annu. Rev. Mater. Sci. 30, 475-521 (2000).

${ }^{45}$ S. H. Wei and A. Zunger, Phys. Rev. B 35(5), 2340-2365 (1987).

${ }^{46}$ R. Beaulac, Y. Feng, J. W. May, E. Badaeva, D. R. Gamelin, and X. S. Li, Phys. Rev. B 84(19), 195324 (2011).

${ }^{47}$ M. A. Alpuche-Aviles and Y. Y. Wu, J. Am. Chem. Soc. 131(9), 3216-3224 (2009).

${ }^{48}$ L. Y. Lu, J. J. Chen, and W. Y. Wang, Appl. Phys. Lett. 103(12), 123902 (2013). 